\title{
EUTHANASIA DI INDONESIA
}

\author{
Oleh: ${ }^{1}$ Herawati \\ (Fakultas Hukum Universitas Asahan) \\ Email: herawati@gmail.com
}

\begin{abstract}
ABSTRAK
Tidak seorangpun yang dapat mengetahui secara pasti bagaimana dan kapan is mati, hidup dan mati adalah di urusan Tuhan Yang Maha Kuasa. Oleh karena itu segala macam perbuatan yang merenggut nyawa manusia adalah perbuatan dosa, sekalipun dilakukan dengan maksud balk, seperti halnya euthanasia, mengakhiri hidup seseorang berhubung adanya penyakit berat yang dialaminya, dengan berbagai macam pertimbangan dan untuk kebaikan si penderita sendiri agar tidak terlalu lama menderita. Di berbagai negara Barat, euthanasia sudah tidak dianggap sebagai pembunuhan, melainkan sesuatu yang boleh dilakukan, lain halnya dengan Indonesia yang berdasarkan Pancasila yang mempunyai pandangan hidup berbeda dengan negara barat. Pancasila sebagai dasar negara Indonesia sangat menghargai hak - hak derajat dan harkat yang diberikan oleh Tuhan Yang Maha Esa, oleh sebab itu euthanasia dilarang di negara Indonesia. Kata Kunci : Euthanasia, Kematian
\end{abstract}

\begin{abstract}
No one can know for sure how and when to die, life and death is in the business of Almighty God. Therefore, all kinds of actions that take human life are sinful, even if they are done with good intentions, such as euthanasia, ending one's life due to a serious illness that one has experienced, with various considerations and for the benefit of the sufferer himself so as not to suffer too long. In various Western countries, euthanasia is no longer considered a murder, but something that can be done, unlike Indonesia which is based on Pancasila, which has a different view of life from western countries. Pancasila as the basis of the Indonesian state really respects the rights of dignity and dignity given by God Almighty, therefore euthanasia is prohibited in the Indonesian state. Keywords: Euthanasia, Death
\end{abstract}




\section{A. PENDAHULUAN}

Dalam konteks saat ini hukum merupakan kebutuhan yang harus disesuaikan dengan tingkat kemajuan pembangunan di berbagai bidang. Sehingga tercapai suatu kepastian hukum guna memperlancar pelaksanaan pembangunan tersebut.

Kemajuan ilmu pengetahuan dan teknologi semakin pesat dengan banyak

nya penemuan-penemuan yang bermanfaat bagi kepentingan manusia, khususnya dalam bidang ilmu kedokteran banyak penemuan obat-obatan dan alatalat medis yang serba modern. Walaupun demikian, manusia tetap tidak dapat melepaskan diri dari berbagai persoalan yang dialaminya, dan menganggapnya sebagai suatu masalah yang belum diketahui secara pasti seperti halnya kesehatan, kelahiran dan kematian.

Khusus kematian tidak seorangpun yang dapat mengetahuinya secara pasti, ka rena masalah hidup dan mati milik Tuhan Yang Maha Esa. Segala macam perbuatan yang merenggut nyawa manusia adalah perbuatan dosa, sekalipun dilakukan dengan maksud baik, seperti halnya "EUTHANASIA", yaitu mengakhiri hidup seseorang berhubung adanya suatu penyakit berat yang dialaminya, dengan berbagai macam pertimbangan dan untuk kebaikan si penderita sendiri agar tidak terlalu lama menderita.

\section{B. HASIL DAN PEMBAHASAN}

1. Perkembangan Euthanasia

Memberikan pengertian atau bata san tentang euthanasia sangat sulit karena tidak ada suatu keseragaman dalam memberikan pengertian, mengingat bahwa hukum itu adalah merupakan suatu bagian dari ilmu sosial, namun demikian para sarjana mencoba memberikan suatu pengertian sebagai pegangan bagi yang hendak mempelajari ilmu hukum khususnya hukum pidana.

Euthanasia berasal dari bahasa yunani, yaitu terdiri dari kata "EU" yang berarti baik, dan "Tanatas" berati mati. Secara keseluruhan euthanasia diartikan sebagai kematian yang senang dan wajar. ${ }^{1}$ Sehingga euthasia biasa didefenisikan sebagai a good death atau mati tenang.

Istilah euthanasia diartikan sebagai mati tanpa penderitaan, atau lebih dikenal dengan istilah "Mercy Killing". Dengan demikian euthanasia adalah perbuatan mengakhiri kehidupan seseorang untuk menghentikan penderitaannya.

Di dalam buku Kode Etik Kedok teran Indonesia, kata euthanasia dipergunakan dalam tiga pengertian yaitu : ${ }^{2}$

1. Berpindah ke alam baka dengan tenang tanpa penderitaan, untuk yang beriman dengan nama Allah dibibir.

2. Ketika hidup akan berakhir, diringankan penderitaan si sakit dengan memberikan obat penenang.

3. Mengakhiri penderitaan dan hidup seseorang yang sakit dengan sengaja atas permintaan pasien sendiri dan keluarganya.

Dalam kumpulan Makalah Temu Ilmiah Perhuki dikemukan bahwa pengertian euthasia adalah tindakan

memper cepat kematian dan memperpendek kehidupan bagi seseorang yang sangat menderita atau kesakitan yang disebabkan oleh penyakit yang tidak mungkin lagi di sembuhkan. ${ }^{3}$

Pada prinsipnya semua pengertian tentang euthanasia hampir bersamaan, karena euthanasia diartikan mati dengan

\footnotetext{
${ }^{1}$ Ratna Suprapti Samil, Kode Etik Keclokteran ndonesia,FK UI, Jakarta 1980, hal 9

2 Ibid, hal 9

3 Suharto, H, Temu Ilmiah VII Perhuki Wilayah Sumatera Utara, Medan, 1990, hal 22.
} 
tenang tanpa suatu penderitaan, sebagai mana yang dikemukan oleh Bachtiar Agus Salim bahwa euthanasia adalah perbuatan yang sengaja memperpendek hidup ataupun dengan sengaja tidak berbuat untuk memper panjang hidup demi kepentingan si pasien oleh seorang dokter atau bawahannya yang bertanggung jawab padanya. ${ }^{4}$

Berdasarkan penjelasan di atas maka euthanasia adalah suatu perbuatan yang dengan sengaja menghilangkan jiwa orang lain, baik dengan mati membebas kan orang lain dari suatu penderitaan yang telah berlarut-larut atau atas permintaan si pasien sendiri maupun keluarganya

Dewasa ini euthanasia merupakan masalah yang menarik perhatian dan banyak dibicarakan orang, sehingga terjadi pertentangan mengenai kemungkinan dilakukannya euthasia. Pertentangan ini pada umumnya adanya dua pendapat yang berbeda, yakni ada golongan yang menyetujui tindakan eutanasia dengan berbagai pertimbangan, dan golongan yang tidak menyetujui tindakan euthanasia dan menganggapnya sebagai suatu pembunuhan terselubung.

Namun di berbagai negara barat, euthanasia sudah tidak dianggap sebagai suatu pembunuhan, melainkan suatu hal yang boleh dilakukan karena hal ini sudah diatur dalam undang-undang seperti yang terdapat di Uruguay. Lain hal dengan negara Indonesia yang berdasarkan demokrasi Pancasila yang mempunyai pandangan hidup berbeda dengan negara barat.

Pancasila sebagai dasar negara Indonesia sangat menghargai hak-hak derajat dan harkat yang sama diberikan oleh Tuhan Yang Maha Esa. Oleh sebab itu euthanasia dilarang di negara Indonesia, karena bertentangan dengan

\footnotetext{
${ }^{4}$ Bactiar Agus Salim, Euthanasia Dan Transolasi Organ Suatu Tinjauan Dari Sudut
}

hidup bangsa, serta Pasal 344 KUHP dimana perbuatan tersebut dapat dianggap suatu delik.

Selanjutnya, sejarah dan Tatar belakang perkembangannya, sejak dibuat nya KUHP sampai sekarang belum ada kuasanya yang nyata di Indonesia yang berhubungan dengan masalah euthanasia. Oleh sebab itu Pasal 344 KUHP ini mengandung berbagai pertanyaan apakah memang benar euthanasia tidak pernah terjadi di Indonesia, ataukah memang perumusan Pasal 344 KUHP sendiri tidak memungkinkan untuk mengadakan penuntutan di muka pengadilan.

Berkaitan dengan masalah euthanasia, secara ringkas dapatlah diuraikan bahwa peristiwa euthanasia ini pernah terjadi pada zaman dahulu kala dan banyak memperoleh dukungan dari tokoh benar dalam sejarah seperti halnya Plato, Aristoteles dan Phythagoras.

Plato mendukung tindakan bunuh diri yang dilakukan oleh orang untuk mengakhiri penderitaan dari penyakit yang dialaminya. Aristotes juga membenarkan infanticide yaitu membunuh anak yang berpenyakitan dari lahir dan tidak dapat hidup menjadi manusia yang perkasa. Phytagoras menyokong perlakukan pembunuh pada orang yang lemah mental dan mora1.

Pendapat beberapa ahli menurut tokoh-tokoh sejarah tentang euthanasia ini, pada masa lalu wajar dilakukan untuk mengakhiri kehidupan yang menderita, tetapi bila dilihat dari segi hak asasi manusia, perbuatan tersebut telah bertentangan, karena setiap pasien memperoleh perawatan seorang dokter, dalam hal ini peranan dokter adalah menyelamatkan penderitaan pasien yang membutuhkan pertolongannya.

Namun seiring kemajuan ilmu pengetahuan dan perkembangan yang

\footnotetext{
${ }^{5}$ Ratna Suprapti Samil, Op. Cit. hal 11
} 
telah dicapai manusia, menimbulkan masalah baru dikalangan dokter dan ahli hukum sehingga hubungan ilmu kedokteran dengan hukum sangat erat sekali dalam masalah euthanasia. Peranan dokter adalah menyelamatkan pasien dan penderitaan yang dialaminya, sedangkan akibat dari perbuatan dokter tersebut hukumlah yang mengaturnya.

Selanjutnya sebagaimana diketahui negara Indonesia adalah negara hukum yang berdasarkan Pancasila, menjunjung tinggi harkat martabat yang sama di sisi Tuhan, oleh sebab itu tindakan membunuh seseorang walaupun atas permintaan dari si pasien tidaklah dibenarkan, karena baik yang menyuruh ataupun yang membantu melakukan pembunuhan tersebut, dihukum dua belas tahun penjara sebagaimana diatur dalam Pasal 344 KUHP.

Ada beberapa pendapat yang membenarkan euthanasia dapat dilakukan seperti menurut Ali Akbar mengatakan bahwa euthanasia dilakukan pada penderitaan gawat darurat yaitu penderita yang karena penyakit seperti kanker dan kecelakaan yang merusak tubuh, sehingga is tidak dapat diharapkan akan sembuh dan hidup. Hal yang sama juga dikemukakan Djoko Prakoso dan Djaman Andi Dir wanto, bahwa tindakan euthanasia dapat dilakukan dengan syarat-syarat sebagai berikut :

1. Bagi pasien yang sudah tidak dapat diharapkan lagi akan kehidupannya menurut medis, yang dinyatakan oleh dokter yang merawatnya.

2. Usaha penyembuhan yang dilakukan selama ini sudah tidak berpontensi lagi

3. Pasien dalam keadaan "in a persistent vegetatif state".

Berdasarkan keterangan di atas

jelaslah bahwa euthanasia dapat dilakukan dengan syarat tersebut di atas, disamping itu juga dapat ditambahkan adanya permohonan tertulis dari pasien atau keluarganya dengan membubuhkan tanda tangan pada surat permohonan tersebut serta ditandatangani oleh saksi.

Selanjutnya euthanasia dibagi dalam beberapa jenis, antara lain menurut Commissie : ${ }^{6}$

1. Vrijwillige Euthasia, euthnasia yang dilaksanakan dengan adanya permintaan yang nyata dan sungguh-sungguh dari sipasien.

2. Onvrijwillege Euthasia, yaitu tidak adanya hal permintaan yang nyata dan sungguh-sungguh dari si pasien.

3. Passsssive Euthasia, yang dimaksud dalam hal ini tidak lagi digunakanalat-alatataupun perbuatan yang dapat memperpanjang hidup pasien.

4. Active Euthasia, menggunakan alat-alat ataupun perbuatan yang memperpendek hidup si pasien.

Ali Akbar membedakan euthanasia ini dalam dua jenis yaitu :

1. Euthanasia aktif, euthanasia aktif dilakukan dengan menghentikan segala alat bantu, sehingga jantung dan pernafasan tidak dapat bekerja dan akan berhenti berfungsi atau memberikan obat penenang dengan dosis yang melebihi, yang juga akan menghentikan fungsi jantung.

2. Euthanasia pasif, dilakukan bila penderita gawat darurat tidak diberi obat sama sekali.

Dari uraian di atas dapat diambil kesimpulan bahwa euthanasia aktif maupun pasif adalah pembunuh yang secara langsung dan tidak langsung. R.

\footnotetext{
${ }^{6}$ Bachtiar Agus Salim, Op Cit, hal 505
} 
Soeprono membagi euthanasia dalam empat jenis yaitu :

1. Euthanasia sukarela, si pasien meminta, untuk menghentikan perawatan yang memperpanjang hidup.

2. Euthanasia terpaksa, membiarkan pasien mati tanpa sepengetahuan si pasien sebelumnya dengan cara menghentikan atau meniadakan perawatan yang memperpanjang hidup.

3. Mercy Killing sukarela, dengan pengetahuan persetujuan pasien diambil tindakan yang menyebabkan kematian.

4. Mercy Killing terpaksa, tindakan sengaja tanpa persetujuan pasien mempercepat kematian

Ke empat jenis euthanasia ini jelas ada perbedaan yang dapat memberi petunjuk atau sikap berdasarkan norma, moral dan etik yang harus dijadikan pegangan, Pro dan kontra mengenai euthanasia tidak luput di masyarakat dengan alasan berbeda-beda. Dalam hubungan kode etik kedok teran Soeprono mengatakan segala perbuatan dokter terhadap si pasien, bertujuan memelihara kesehatan dan kebahagiaan.

Berkaitan dengan masalah euthanasia, J.E. Sahetapy membedakan euthanasia ke dalam tiga jenis, yaitu : 8

1. Action to permit death to occur, kematian dapat terjadi karena si pasien dengan sungguh-sungguh dan secara cepat menginginkan untuk mati.

2. Failure to take action to prevent death, kematian terjadi karena kelalaian atau kegagalan dari

\footnotetext{
${ }^{7}$ Soeprono. R, Catatan Tentang Ketnatian Dan Euthanasia, Majalah Panji Masyarakat, Nomor 318 Medan, 1981, hal 80

${ }^{8}$ Djoko Prakoso dan Djaman Andhi Niwanto, Euthanasia , Hak Asasi Manusia Dan Hukum Pidana, Ghalia Indonesia, Jakarta, 1984, hal 73
}

seorang dokter dalam mengambil suatu tindakan untuk mencegah adanya kematian.

3. Positive action to couse death, tindakan yang positif dari dokter untuk mempercepat terjadinya kematian

Perkembangan euthanasia di Indonesia, ditinjau dari segi perundangundangan dewasa ini, belum ada peraturan yang mengatur tentang euthanasia. Namun karena masalah ini menyangkut tentang keselamatan jiwa manusia, maka perlu dicari pengaturannya atau pasal yang mendekati unsur euthanasia tersebut. Satu-satunya pasal yang dapat dipakai sebagai landasan hukum yang terdapat di dalam KUHP adalah Pasal 344 KUHP.

Di dalam Pasal 344 KUHP, disebutkan bahwa "Barang siapa meram pas nyawa orang lain atas permintaan sen diri yang jelas dinyatakan dengan kesungguhan hati, diancam dengan pidana pen jara paling lama dua belas tahun". Dari bu nyi pasal tersebut jelas bahwa euthanasia tidak dapat dilakukan sekalipun atas permintaan si pasien sendiri dengan kesungguhan hati.

Bagi kalangan kedokteran jelas bahwa pasal yang terdapat dalam KUHP tidak membenarkan pelaksanaan euthana sia, kecuali bilamana tindakan euthanasia tidak diartikan sebagai tindakan kejahatan sebagaimana yang dimaksud dalam KUHP.

Untuk itu perlu dipikirkan bila memang euthanasia merupakan masalah yang mendesak, maka perlu dibuatkan

suatu perundang-undangan yang mengatur masalah tersebut, sehingga kalangan kedokteran dapat tentram melakukan tindakan yang berkenaan dengan masalah tersebut.

Agar Pasal 344 KUHP tidak disalahgunakan maka unsur "permintaan sendiri yang dinyatakan dengan 
kesungguhan hati" haruslah dapat dibuktikan dalam hal timbul masalah, bagaimana jika yang bersangkutan tidak mampu lagi berkomunikasi dalam bentuk atau cara apapun sehingga tidak dapat dinyatakan dengan kesungguhan hati, kita ketahui bahwa dalam masalah euthanasia si pasien dalam keadaan mati tidak, hidup pun tidak (in a persisten vegetative state).

Sebagai contoh kasus Karen Ann Quilan yang terjadi Amerika Serikat. Keadaannya tersebut in a persisten Vegetative state (mati tidak, hidup pun tidak). Karen hanya dapat bertahan dengan bantuan respirator. Keadaannya bagaikan patung bertulang terbungkus kulit yang semata-mata bagaikan kerangka mayat. Dalam hal ini dapatkah kita katakan bahwa Karen masih hidup? Bukankah Karen tidak dapat berbicara lagi? Jangankan makan, segala sesuatu untuk hidup bergantung dari mesin-mesin modern. Para ahli kedokteran mengatakan bahwa apabila respirator tersebut dilepaskan, maka Karen akan segera mati, karena is membutuhkan waktu 24 jam terus menerus dalam perawatan intensive. 9

Dalam hal kasus di atas, maka Pasal 344 KUHP sulit diterapkan. Selanjutnya di Indonesia data yang pasti tentang euthanasia belum ada, namun perdebatan tentang masalah ini sudah dimulai, karena euthanasia telah menjadi masalah etik yang penting. Dengan kemajuan teknologi biomedis yang sangat pesat,

ilmu kedokteran mampu untuk memperpanjang hidup seseorang, alat bantu kehidupan seperti respirator, ginjal bantuan dan suplai makanan melalui infus, telah memungkinkan seseorang untuk bertahan hidup, walaupun secara alamiah seseorang telah kehilangan kemampuan untuk bertahan hidup.

\footnotetext{
${ }^{9}$ Ibid, hal. 102
}

Euthanasia secara sempit ditafsirkan sebagai kematian yang baik, namun

ada yang menganggapnya sebagai pembunuhan sehingga selalu dianggap salah. Penafsiran yang lebih luas dari euthanasia tidak hanya tindakan mencabut nyawa seseorang tetapi tindakan membiarkan seseorang mati juga dianggap euthanasia.

Perbedaan antara membunuh dengan membiarkan seseorang mati merupa kan suatu hal yang cukup sulit untuk dipisahkan. Menurut John Lorber dari Ameri can Medicice Association, antara membunuh dengan membiarkan mati dapat dibedakan dengan tegas.

Perbedaannya, pembunuh adalah menyebabkan kematiaan, sedangkan membiarkan mati adalah membolehkan kematian terjadi. Yang kedua adalah sebab terjadinya kematian oleh penyakit yang di deritanya atau tidak adanya pengobatan. 10

Hal yang sama dikemukan juga oleh James Rachels dalam bukunya Contenporary Inssues of Biothic menya takan bahwa membiarkan mati seseorang adalah suatu tindakan, bukan kelalaian oleh sebab itu is menganggap perbedaan itu tidak ada. Pada prinsipnya tidak sama semua orang menyetujui tindakan euthanasia, demikian juga halnya dengan para dokter. Sebahagian masyarakat bertitik to lak dengan alasan relegius, sehingga sega la sesuatunya merupakan kehendak Tuhan.

Argumentasi yang dikemukan para dokter sesuai dengan kode etik kedokteran Indonesia, yang juga mencerminkan sikap atau pandangan para dokter di Indonesia tentang euthanasia sebaliknya bagi kelompok yang menyetujui perbuatan euthanasia dengan argumentasi bahwa perbuatan ter sebut

\footnotetext{
10 John Lorber, American Medicine Association, "Majalah Matra", Nomor 83, Jakarta, 1993, hal 51
} 
terpaksa dilakukan atas dasar kema nusiaan. Mereka tidak tega melihat penderitaan diakhiri saja. Sehubungan dengan itu R.Soerarjo Darsono memberikan contoh kasus sebagai berikut

Seorang wanita yang telah hamil tua, kemudia mengalami kecelakaan yang sangat parah, sehingga lehernya putus dengan demikian wanita tersebut telah mati. Masalahnya sekarang bagaimana dengan bayi yang masih berada di dalam perut sang ibu, yang menurut dolcter. diperkirakan masih hidup. Bagaimana sikap dokter dalam hal ini. Ada dua pendapat diantara para dokter yang mengatakan :

1. Harus dibuka demi keselamatan dan kelangsungan hidup si bayi tersebut.

2. Biarkan saja, biar tuhan sendiri yang melahirkannya.

Sejalan dengan itu maka dalam dunia kedokteran, bagi orang yang menyetujui tindakan euthanasia atas dasar kemanusiaan, terhadap seseorang yang menderita sakit dan tidak dapat disembuh kan lagi. Mungkin dapat ditempuh jalan tengah yang bertitik tolak pada prinsip euthanasia, demikian juga halnya bagi orang yang tidak menyetujui tindakan euthanasia mengatakan bahwa segala sesuatu yang dialami manusia sudah menjadi kehendak Tuhan.

Namun Tuhan juga mewajibkan manusia untuk berusaha menghilangkan penderitaannya. Dalam hal ini pengobatan untuk menyembuhkan dan menghilangkan penderitaan sudah tidak memungkinkan lagi, sedangkan jalan satu-satunya ialah mengakhiri hidup si pasien agar penderitaannya dapat segera berakhir. Hal seperti inilah yang sering terlihat, disamping kematian memang

diminta oleh si pasien untuk menghilangkan penderitaannya.
Euthanasia sebagai hak yang diberikan kepada pasien atas dasar kesimpulan teknologi medis bahwa is tidak dapat disembuhkan, maka untuk mempercepat proses kematiannya dengan bantuan dokter dan lain-lain, maka pelaksanaan euthana sia memerlukan berbagai keputusan, baik dari segi hukum formal, kode etik kedok teran, maupun pengakuan dari pasien dan keluarganya dalam hal ini dokter akan melaksanakan tindakan euthanasia terhadap pasiennya sesuai dengan kewajiban dan penuh tanggung jawab tanpa merasa bersalah atau dipersalahkan, atau tanpa me langgar hukum dan kode etik kedokteran, sehingga proses yang berlangsung tetap dalam konteks interaksi dokter dengan pasien secara wajar.

Sering ditemukan bahwa pasien yang mengalami penyakit parah selama berbulan-bulan mendapat perawatan intensif, dibawa pulang oleh keluarganya, dan akan meninggal di rumah dengan tenang disamping keluarganya. Hal ini disebabkan karena pihak keluarga sudah mendapat kepastian dari dokter yang merawatnya, bahwa sudah tidak ada harapan untuk sembuh, dan juga tidak ingin memperpanjang penderitaan si pasien.

Contoh Kasus : DS adalah seorang Dosen yang berumur 38 Tahun di indikasikan menderita penyakit lever.

Tim dokter yang merawatnya mengatakan bahwa harapan DS untuk sembuh sudah tidak ada lagi, sehingga keputusan diserahkan kepada pihak keluarganya, apakah dirawat terus atau dibawa pulang. Namun DS sendiri setuju untuk pulang ke rumah dan kurang lebih 3 bulan di rumah DS meningga1. ${ }^{11}$

Banyak lagi contoh kasus yang timbul dipermukaan, kalau dalam kasus di atas si pasien sendiri yang memintanya, dan ada

\footnotetext{
${ }^{11}$ Ibid, hal. 52
} 
juga yang tanpa permintaan atau persetujuan pasien, karena si pasien dalam keadaan koma terus menerus, hanya saja pihak keluarga meminta kepada dokter untuk menghentikan alat bantu yang digunakan setelah pihak keluarga men dapat kepastian dari dokter bahwa pasien tidak dapat bertahan lebih lama tanpa alat bantu tersebut dan kemudian mcninggallah pasien tersebut.

Dari kasus di atas, dapat disimpul kan bahwa pasien menolak pelayanan me dis karena is memiliki hak untuk itu. Da lam kasus euthanasia pasif ini, sebagai mana yang dikemukakan oleh Heleen $\mathrm{M}$. Dupuis bahwa "euthanasia pasif yang dilakukan dokter atas permintaan pasien tidak akan diganjar dengan sanksi pidana".

Banyak kasus euthanasia pasif yang terjadi di Indonesia, namun tidak pernah

muncul ke permukaan, karena masyarakat menganggapnya sebagai suatu hal yang biasa atau wajar dilakukan. Sejak terbentuknya KUHP sampai sekarang belum ada kasus yang nyata di Indonesia yang berhubungan dengan euthanasia sebagaimana yang di atur dalam Pasal 344 KUHP.

Apakah kasus ini pernah terjadi di Indonesi ? ataukah perumusan Pasal 344 KUHP tersebut tidak memungkinkan me ngadakan tuntutan di pengdilan ? Pasal 344 KUHP perlu ditinjau kembali, apakah perbuatan euthanasia merupakan suatu perbuatan yang tidak dilarang dengan mencantumkan syarat tertentu.

Dengan demikian Pasal 344 KUHP sulit untuk diterapkan, terlepas dari berat ringannya sanksi yang diancam, maka pasal 344 KUHP masih tetap dipertahankan karena mencerminkan hak asasi manusia untuk hidup terus, disamping pa sal tersebut mengandung makna bahwa jiwa manusia harus dilindungi, tidak saja dari ancaman orang lain, tetapi juga dari usaha orangnya sendiri untuk mengakhiri hidupnya.

Dalam rangka pembaharuan hukum pidana, maka Pasal 344 KUHP ter sebut perlu dirumuskan kembali, untuk da pat memudahkan penuntut umum dalam hal pembuktian kasus euthanasia. Hal ini disebabkan:

1. Bila terjadi masalah yang berhubungan dengan pasal tersebut, tidak perna dilaporkan kepada Polisi, atau pejabat yang berwenang.

2. Kebanyakan orang Indonesia masih awam terhadap hukum, apalagi terhadap Euthanasia yang diatur dalam Pasal 344 KUHP.

3. Alat-alat kedokteran di Indonesia belum begitu modern, sehingga jarangterjadipencegahan kematian secara teknis untuk beberapa waktu tertentu. ${ }^{12}$

Euthanasia tetap dilarang sesuai dengan Pasal 344 KUHP yang sampai sekarang masih berlaku, oleh sebab itu Pasal 344 KUHP perlu dirumuskan kembali berdasarkan kenyataan yang terjadi dan diselesaikan dengan perkembangan medis.

\section{KESIMPULAN}

1. Perkembangan euthanasia di Indonesia ditinjau dari segi perundang- undangan dewasa ini belum diatur, namun karena masalah ini menyangkut tentang keselamatan jiwa manusia, maka perlu dicari pengaturannya.

2. Pasal344KUHPtidak membenarkan pelaksanaan euthanasia, kecuali bilamana tindakan euthanasia tidak diartikan sebagai tindakan kejahatan.

\section{DAFTAR PUSTAKA}

\footnotetext{
${ }^{12}$ Djoko oko Prakoso, Djaman Andhi Nirwanto, Op.Cit. hal 106
} 
H. Suharto, Temu Ilmiah VII Perhuki Wilayah Sumatera Utara, Medan Tahun 1990

Lorber John, American Medicine Association, "Majalah Matra", Nomor 83, Jakarta, Tahun 1993

Prakoso Djoko dan Niwanto Djaman Andhi, Euthanasia, Hak Asasi Manusia Dan Hukum Pidana, Ghalia Indonesia, Jakarta, Tahun 1984

R. Soeprono., Catatan Tentang Kematian Dan Euthanasia, Majalah Panji Masyarakat, Nomor 318 Medan, Tahun 1981

Salim Bactiar Agus, Euthanasia Dan Transolasi Organ Suatu Tinjauan Dari Sudut Pandang Hukum Pidana, Majalah Hukum Dan Pembangunan, Nomor 112, Medan, Tahun 1983

Samil Ratna Suprapti, Kode Etik Kedokteran Indonesia, FK UI, Jakarta, 1980

Salim Bactiar Agus, Euthanasia Dan Transolasi Organ Suatu Tinjauan Dari Sudut Pandang Hukum Pidana, Majalah Hukum Dan Pembangunan, Nomor 112 , Medan, Tahun 1983

Samil Ratna Suprapti, Kode Etik Kedokteran Indonesia, FK UI, Jakarta, 1980 